\title{
(1) $\mathbb{E} \mathbb{N} \mathbb{R} \mathbb{N} \mathbb{D} \mathbb{M} \mathbb{E} \mathbb{N} O \quad \mathbb{D}$
}

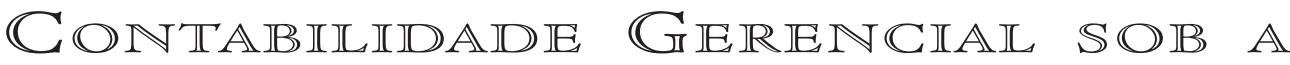

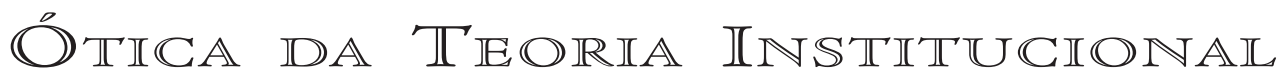

\author{
Reinaldo Guerreiro * \\ Fábio Frezatti ** \\ Alexsandro Broedel Lopes $* * *$ \\ Carlos Alberto Pereira $* * * *$
}

$\mathbb{R} \mathbb{E} \mathbb{S U M}_{\mathbb{O} O}$

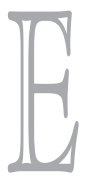

ste trabalho tem como objetivo refletir sobre o paradoxo da estabilidade dos sistemas de contabilidade gerencial, ou seja, sobre as razões pelas quais as organizações, na prática, utilizam muito pouco a base conceitual disponível na teoria. A base conceitual da teoria da contabilidade gerencial é fundamentada na teoria neoclássica da firma, cujos pressupostos básicos são: (i) a maximização racional dos agentes econômicos e (ii) o equilíbrio geral proporcionado pelas forças de mercado. O estudo de caráter teórico apresenta críticas à teoria neoclássica e demonstra que, segundo a abordagem da denominada velha economia institucional (OIE - old institutional economics), a contabilidade gerencial praticada pelas empresas é uma instituição formada a partir de hábitos e rotinas que dão sentido aos relacionamentos dos grupos da organização. O estudo indica que as organizações não utilizam em larga escala as novas abordagens de contabilidade gerencial porque os processos de institucionalização dos novos conceitos efetivamente não ocorreram.

\section{$\mathbb{A B S T R A C T}_{\mathbb{R}}$}

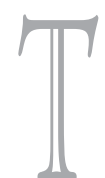

his study aims to carry out reflections towards explaining the paradox of management accounting stability, or, why the implementation level of new accounting techniques and concepts in companies is below the expected. Management accounting theory is strongly oriented by the neoclassical theory of the firm, but neoclassical economics was developed by economists to predict behavior at the industry and market levels. It was not intended as an explanation of the behavior of managers within firms. This paper criticizes neoclassical theory and argues that according the OIE - old institutional economics, management accounting can be seen as institution formed through habits and routines of a social group. The institutional approach enables organizations to reproduce and legitimate behaviors and to achieve organizational cohesion. This work indicates that firms do not implement new concepts from management accounting because these were not institutionalized. 
esquisas empíricas apresentadas neste trabalho constatam que existe atualmente um aparente paradoxo no que diz respeito à prática da contabilidade gerencial. Apesar de fatores indutores e facilitadores do ambiente externo e do rol de novas técnicas e procedimentos à disposição dos gestores empresariais, o que se observa efetivamente, na prática, é o baixo grau de implementação de novas técnicas e procedimentos de contabilidade gerencial nas empresas. A questão que se coloca é: por quê?

Este trabalho tem como objetivo refletir sobre o paradoxo da estabilidade dos sistemas de contabilidade gerencial, ou seja, por que as organizações, na prática, utilizam muito pouco a base conceitual disponível na teoria. É realizada uma crítica à teoria neoclássica - que tem se constituído na base filosófica predominante na orientação do desenvolvimento de sistemas de contabilidade gerencial - e apresentada a teoria institucional como uma visão alternativa para o estudo e entendimento da prática da contabilidade gerencial nas empresas.

Durante os anos 80, inúmeros autores, dentre os quais destacam-se Johnson e Kaplan (1987), levantaram a questão da relevância da contabilidade gerencial em ambiente de crescente competição global e mudanças revolucionárias na gestão operacional das empresas. Às críticas, seguiu-se uma série de prescrições para melhorar a relevância da contabilidade gerencial no novo ambiente. No trabalho de Coad (1999, p.115), são apresentadas as principais abordagens sugeridas com maior freqüência:
Activitiy based costing - ABC (Custeio Baseado em Atividades), activity based management - ABM (Gestão Baseada em Atividades), throughput accounting, (Contabilidade de Ganhos), life cycle costing (Custeio do Ciclo de Vida do Produto), value chain approaches to strategic management (Abordagem de Cadeia de Valor para Gestão Estratégica), the accounting assessment of competitive position (Avaliação Contábil de Posição Com- petitiva), qualitative performance measures (Medidas de Desempenho Qualitativas), balanced scorecard - BSC, target costing (Custeio Meta), kaizen cost management (Administração de Custos Kaizen).

A esse rol de novas abordagens podem ser adicionados ainda os conceitos de EVA - economic value added (Valor Econômico Agregado) e Gecon - sistema de gestão econômica.

No trabalho de Burns e Scapens (2000, p. 21), é apresentada a frase de di Lampedusa: "Se nós queremos que coisas permaneçam como estão, coisas terão que mudar". O tema da estabilidade e da mudança nos sistemas de contabilidade gerencial tem sido pouco explorado em pesquisas no Brasil, por outro lado constitui-se em tema relevante de pesquisa acadêmica no exterior, principalmente na Europa. A importância desse tema de pesquisa é de tal ordem que a revista acadêmica Management Accounting Research dedicou a edição completa do seu volume 12, em 2001, para a publicação de artigos versando sobre essa temática. O estudo de Hopwood (1987) sobre os desafios das mudanças contábeis ilustra a variedade e complexidade desse processo. A contraparte da mudança, a estabilidade, também é igualmente enfatizada nos estudos de contabilidade. A estabilidade e a mudança dos sistemas de contabilidade gerencial podem ser enfocadas como fenômenos interconectados. O estudo dos fenômenos da estabilidade e da mudança pode ser efetuado sob diferentes abordagens ou teorias, sendo as principais: a Teoria Institucional, a Teoria da Contingência e a Teoria da Estruturação. Neste trabalho, é empregada a Teoria Institucional como abordagem para entendimento dos fenômenos da estabilidade e da mudança nos sistemas contábeis gerenciais. 
(1) $\mathbb{A} \mathbb{M} \mathbb{B} \amalg \mathbb{E} \mathbb{N}$ SOCIAL $\mathbb{E}$

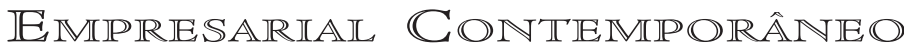

A sociedade, notadamente a partir dos anos 80 do século passado (Baines; Langfield-Smith, 2003), constitui-se em ambiente muito diferente do ambiente social das décadas anteriores. As diferenças são significativas e passam por um novo elenco de valores aceitos pelas pessoas, por novas formas de organização social, pela valorização do conhecimento, pelo fortalecimento extremado do capitalismo, pela desregulamentação de mercados, por novas formas de financiamento das economias, pela intensificação da acumulação de capital, pelas novas estruturas de fluxos dos recursos financeiros, pela intensificação do processo de comunicação decorrente do desenvolvimento tecnológico etc.

No âmbito das empresas, podem-se observar diferenças profundas em relação ao ambiente das décadas anteriores no que diz respeito às novas formas de produção; à utilização intensa de novos frutos do desenvolvimento tecnológico, tanto na atividade de produção de bens e serviços como nas formas de comunicação; à especial atenção com o atendimento das necessidades dos clientes; à atuação em ambiente extremamente competitivo; à atuação em mercados globalizados, dentre inúmeras outras características.

Do ponto de vista contábil, evidencia-se a grande preocupação com o valor das empresas em função dos crescentes processos de privatizações e de fusões, além das novas formas de financiamento das empresas via mercado de capitais. A mensuração do valor do ativo intangível torna-se fundamental em decorrência da crescente importância do capital intelectual e das empresas de e-business, em que $o$ ativo tangível possui pequena relevância.

Os modelos decisórios dos gestores das empresas nesse ambiente atual são orientados por novas variáveis ambientais. Esses novos modelos decisórios demandam novas informações que devem ser estruturadas a partir do emprego de novos conceitos de contabilidade gerencial, conjugados com antigos conceitos que permanecem válidos à luz da realidade do novo ambiente. Baines e LangfieldSmith (2003) afirmam que é um tema comum na pesquisa em contabilidade gerencial o fato das mudanças no ambiente externo das organizações conduzirem a mudanças nos sistemas de contabilidade gerencial das empresas. Essa afirmativa fundamenta-se na idéia de que os gestores demandam informações gerenciais específicas para suportar suas necessidades de tomada de decisões em ambiente de crescente incerteza e monitorar o progresso no alcance de estratégias.

As principais características do atual ambiente social e empresarial constituem-se em fatores indutores de processos de mudanças; em tese, as empresas são forçadas a implementar processos de mudanças profundos na sua forma de atuação, no seu modelo de gestão de negócios, nos seus instrumentos gerenciais e, portanto, na contabilidade gerencial. Granlund e Lukka (1998) utilizam o conceito de direcionadores de convergência e divergência na argumentação de que existe atualmente uma tendência no sentido da convergência dos conceitos e concepção de sistemas de contabilidade gerencial em termos globais.

Além dos desafios atuais que devem impulsionar as empresas em direção à implementação de processos de melhoria contínua, existem outras características contemporâneas, ou seja, fatores facilitadores do processo de mudanças nos sistemas de contabilidade gerencial. Dentre esses fatores facilitadores podem ser destacados: (i) maior volume de informações disponíveis, por meio de publicações acadêmicas, livros técnicos e revistas; (ii) maior facilidade de acesso às informações, principalmente em função da Internet e das novas tecnologias de informação; (iii) melhor formação acadêmica dos executivos da área contábil, devido principalmente ao atendimento de cursos de especialização, cursos do tipo MBA e cursos à distância; e (iv) emprego de novas tecnologias de informação no ambiente empresarial, dentre as quais se destacam os denominados sistemas ERP, a transmissão de dados via satélite e a Internet. 
Os três primeiros fatores têm um impacto específico nos profissionais da contabilidade gerencial, fazendo com que esses executivos tenham acesso aos novos conceitos e técnicas disponíveis. O quarto fator tem um impacto no ambiente operacional da empresa, facilitando a operacionalização de novos conceitos e também dos antigos conceitos que eram de difícil operacionalização no ambiente das antigas tecnologias de processamento de dados e transmissão de informações. Em síntese, esses fatores tornam-se facilitadores da implementação de conceitos gerenciais modernos, propiciando à contabilidade gerencial assumir o papel de instrumento de gestão importante para subsidiar as organizações no enfrentamento dos desafios do mundo atual.

\section{O $\mathbb{E} \mathbb{E} \mathbb{N} O \mathbb{M} \mathbb{N}$ NO DA ESTABILIDADE DOS}

\section{SISTEMAS DE CONTABILIDADE GERENGIAL}

... é provavelmente razoável dizer que as práticas contábeis geralmente demoram a mudar. Uma questão interessante é: por quê? (Scapens, 1994, p. 317)

A despeito da existência de fortes fatores indutores e facilitadores para a modernização da contabilidade gerencial, ela pouco tem se modificado. Diversos autores e pesquisadores têm alertado para o problema do que se pode denominar de "estabilidade da contabilidade gerencial", chamando a atenção para o fato de que a pesquisa contábil tem tido pouco impacto na prática empresarial e, também, para as diferenças existentes entre o que diz a teoria e o que é feito na prática. Diversos trabalhos, desde o início da década de 90, de forma direta ou indireta, abordam esse tema, destacando-se Otley (1985), Choudhury (1986), Johnson e Kaplan (1987), Edwards e Emmanuel (1990), Cohen e Paquette (1991), Brigth et al. (1992), Emore e Ness (1991), Green e Amenkhienan (1992), Ask e Ax (1992), Drury et al. (1993), Scapens e Roberts (1993), Scapens (1994), Covaleski et al. (1996), Evans e Ashworth (1996), Libby e Waterhouse (1996), Granlund e Lukka (1998), Burns (2000), Burns e Scapens (2000) e Granlund (2001).

Green e Amenkhienan (1992) mencionam que existe um descompasso significativo entre inovações em manufatura e inovações na contabilidade gerencial. Embora mudanças estejam ocorrendo, as empresas, em grande extensão, continuam a apoiar-se em modelos contábeis desatualizados. Bright et al. (1992) também têm opinião semelhante, afirmando que é possível observar que muitas empresas estão ainda ativamente trabalhando na introdução e desenvolvimento do que muitos observadores poderiam caracterizar como sistemas de custeio tradicionais. Granlund (2001) menciona que um fato freqüentemente observado é que os sistemas contábeis são difíceis de mudar, apesar da influência das mudanças significativas no mercado e de outras mudanças que colocam grande pressão sobre a contabilidade para que esta se modifique.

Utilizaremos, como um exemplo ilustrativo de moderna técnica de contabilidade gerencial com baixo nível de implementação prática, o sistema de custeio baseado em atividades (Activity Based Costing - ABC). O sistema baseado em atividades tem sido, desde a sua concepção no final da década de 80 , o assunto da contabilidade gerencial mais pesquisado e divulgado academicamente, bem como considerado um dos mais modernos produtos de venda das empresas de consultoria.

A pesquisa desenvolvida por Riccio, Segura e Sakata (2000), objetivando analisar a composição temática dos trabalhos científicos de custos publicados no período de 1967 a 1999 no Brasil, demonstra o volume de publicações relativo ao sistema $A B C$, no qual a área temática "teoria contábil de custos" representa $44 \%$ de todos os trabalhos publicados, sendo que, desse total, $38 \%$ são trabalhos relacionados ao sistema $A B C$. 
Sobre esse sistema, Ask e Ax (1992) afirmavam que existe pouca evidência de que o sistema $A B C$ ou outra nova técnica tenha sido adotada pelas companhias. Evans e Ashworth (1996) mencionam que somente $21 \%$ das companhias têm, na verdade, feito algo em termos de introdução do sistema $A B C$ e, dentre essas, apenas $28 \%$ têm introduzido efetivamente o sistema.

Fechner (1999, p. 8-19), analisando os resultados de pesquisas empíricas sobre a aplicação do sistema $A B C$, menciona que esse tem sido um sucesso, porém restrito, se comparado com técnicas tradicionais de contabilidade gerencial, relatando que: "Resultados de pesquisas sobre a adoção e implementação do $A B C$ indicam que em países como Estados Unidos, Canadá, Austrália, Japão e em alguns países europeus, a taxa de aceitação/implementação varia entre $6 \%$ a $12 \%$ no âmbito industrial $[\ldots] "$.

Horngren, Foster e Datar (2000, p. 80) evidenciam o interesse crescente das empresas pelo custeio baseado em atividades, tendo em vista os resultados de várias pesquisas efetuadas na prática empresarial em diferentes países. Os autores apresentam evidências de que a implementação prática desse sistema ainda é bastante reduzida: "Entre as empresas canadenses, um levantamento indicou que $14 \%$ dos negócios entrevistados implementaram o $A B C$ e $15 \%$ estão pensando em adotá-lo [...] Um levantamento feito no Reino Unido identificou que menos de $20 \%$ dos entrevistados adotaram o $A B C[\ldots]^{\prime \prime}$.

Os resultados das pesquisas demonstram o descompasso entre a teoria e a prática da contabilidade gerencial e o baixo nível de implementação prática de novos sistemas de contabilidade gerencial, mesmo aqueles com maior divulgação como é o caso do sistema $A B C$.

\section{CRIITICAS A TEORIA NEOCLÁSSICA}

O conhecimento contido na teoria convencional (conventional wisdom), ou seja, a forma usualmente aceita de como as coisas devem ser feitas, foca a mudança na contabilidade como um produto de um comportamento racional que busca maximizar o lucro da empresa por meio da geração de [novas] informações eficazes, visão esta fundamentada na teoria econômica da firma neoclássica (Burns, 2000). A essa idéia se contrapõe a visão de mudança como um processo dinâmico no decorrer do tempo, caracterizada pela teoria institucional, sendo observado que a adoção do enfoque institucional como insight teórico para explorar processos de mudanças contábeis é recente. Santos (2003) menciona que o institucionalismo surge da divergência com a linha ortodoxa do pensamento econômico, que distorce a realidade querendo explicá-la pelo uso de modelos extremamente abstratos e matemáticos e desconsiderando o ambiente institucional que condiciona a política econômica.

O conhecimento teórico no âmbito da contabilidade gerencial é fortemente orientado pela teoria neoclássica da firma, mas essa teoria não se constitui em referencial teórico adequado para explicar o desenvolvimento de sistemas de contabilidade gerencial (Scapens, 1994). A teoria neoclássica foi desenvolvida por economistas para ajudá-los a prever comportamentos, efetuar estudos e análises no âmbito da indústria e do mercado como um todo. Não havia intenção de explicar o comportamento de gestores dentro das firmas. Duas pressuposições são importantes no âmbito da teoria neoclássica da firma: (i) a maximização racional dos agentes econômicos e (ii) o equilíbrio geral proporcionado pelas forças de mercado. O pressuposto da racionalidade econômica dos indivíduos considera que esses estarão sempre tomando individualmente decisões racionais. Assim, todas as demais dimensões que cercam o ser humano, principalmente a psicológica e a sociológica, são desconsideradas na análise econômica do modelo neoclássico. O equilíbrio do mercado é visto como uma conseqüência dos comportamentos econômicos individuais, considerando que o todo é formado pela soma das partes, e não considerando outras variáveis externas ao modelo da racionalidade econômica. 
Pela influência da escola neoclássica, a racionalidade econômica dos indivíduos e dos agentes do sistema econômico foi transferida para dentro das empresas. Nesse contexto, os funcionários, gestores e donos dos empreendimentos são considerados agentes econômicos racionais, e a contabilidade gerencial tem uma única missão: prover informações adequadas para que os tomadores de decisões maximizem o resultado econômico de suas decisões. Como conseqüência, os estudos da contabilidade são desenvolvidos sob essa orientação, buscandose a estruturação dos modelos de decisão mais adequada, os melhores conceitos de mensuração, as melhores soluções de sistema, etc. que levem à maximização do lucro da empresa. Fonseca e Machado da Silva (2002) esclarecem que, na abordagem institucional, não se exclui a possibilidade de existirem organizações predominantemente orientadas pela lógica da eficiência, nas quais privilegia-se a natureza técnica do processo produtivo. No entanto, em sua essência, o conceito de organização, sob o enfoque institucional, baseia-se no desencadeamento do processo de institucionalização e no seu efeito sob a ação.

Existe uma profusão de modelos "ideais" no campo da contabilidade gerencial que surgiram há pouco mais de uma década, tendo como pressuposto a racionalidade do tomador de decisão, mas as pesquisas empíricas demonstram que as empresas quase não estão usando esses novos modelos. A questão fundamental é: por que os gestores não utilizam esses novos modelos para a otimização dos resultados dos negócios? Ou os modelos não são adequados, ou os gestores não são guiados prioritariamente pela racionalidade econômica, ou seja, outros fatores de importância igual ou superior exercem influência. Scapens (1994, p. 303) resume o objetivo do seu trabalho mencionando: "Assim a mensagem deste artigo para os pesquisadores em contabilidade gerencial é: não importa o gap, estude a prática da contabilidade gerencial".

Ryan et al. (2002) discutem as diferenças entre a teoria neoclássica normativa e a positiva. Os autores mencionam que a teoria normativa é baseada na construção de recomendações acerca da prática empresarial baseada nos princípios econômicos fundamentais. Tradicionalmente, as pesquisas dentro dessa linha ignoram os custos de transação, conflitos de agência, assimetrias informacionais e quaisquer outros problemas que abalem a construção teórica tradicional do modelo clássico. Por outro lado, a teoria clássica positiva parte da existência dos problemas supracitados e tenta construir representações da realidade que sejam passíveis de testes empíricos. Para a contabilidade gerencial, a visão normativa possui enorme influência no âmbito conceitual. A maior parte dos textos de contabilidade gerencial está baseada em um modelo da firma no qual não existe a pressuposição de problemas informacionais. Em certo sentido, é um tanto surpreendente que a teoria da contabilidade gerencial tradicional tenha baseado-se em um modelo da firma no qual não existem problemas de informação. Em um modelo tão estilizado da firma como esse, cabe perguntar qual seria a função da contabilidade. Pode-se ver claramente que a visão simplificada da teoria da firma apresentada pela teoria clássica normativa não é adequada para explicar os fenômenos contábeis. A contabilidade surge justamente pela existência de problemas de informação e coordenação em organizações nas quais os gestores não possuem interesses plenamente alinhados.

\section{$\mathbb{T} \mathbb{E} O \mathbb{R} I \mathbb{A}$ INSTITUCIONAL}

Fonseca e Machado da Silva (2002) observam que os partidários da abordagem institucional consideram que o comportamento individual é modelado por padrões criados e compartilhados na interação, mas incorporados na forma de normas e regras objetivas, cristalizadas na sociedade como concepções legitimadas sobre a maneira mais eficaz de funcionamento das organizações. O interesse pela teoria institucional nas ciências sociais tem aumentado, e três enfoques dessa teoria podem ser observados na literatura contábil: (i) nova sociologia 
institucional (NIS - new institutional sociology), (ii) nova economia institucional (NIE - new institutional economics) e (iii) velha economia institucional (OIE - old institutional economics). Embora essas teorias tenham diferentes origens e raízes filosóficas diversas, elas compartilham um interesse comum pelos temas instituição e mudança institucional. Nesta seção, são abordadas as diferentes correntes teóricas institucionalistas e, nas seções seguintes, é efetuada a reflexão da estabilidade dos sistemas de contabilidade gerencial com base na corrente teórica da velha economia institucional (OIE - old institutional economics).

\section{NOVA SOCIOLOGIA INSTITUCIONAL ( NIS -} NEW IINSTITUTIONAL SOCIOLOGY)

A teoria da NIS (Dimaggio e Powell, 1983; Meyer e Rowan, 1977; Scott, 1995; Zucker, 1987) enfoca as organizações configuradas dentro de uma grande rede de relacionamentos inter-organizacionais e sistemas culturais. $O$ ambiente institucional não apenas influencia o relacionamento das organizações com o mercado, mas também suas crenças, normas e tradições. Além do mais, o ambiente institucional é caracterizado pela elaboração de regras, práticas, símbolos, crenças e requerimentos normativos aos quais indivíduos e organizações precisam se conformar para receber apoio e legitimidade.

De acordo com Covaleski et al. (1996), o tema geral da perspectiva da denominada nova sociologia institucional (NIS) considera que, para assegurar a sua sobrevivência, a organização precisa conformar-se às normas sociais de comportamento aceitável, além de atingir níveis de eficiência produtiva. O pensamento sociológico weberiano caracteriza a estrutura organizacional como um veículo adaptativo moldado em reação às características e compromissos dos participantes, bem como às influências e restrições do ambiente externo. Nesse contexto, a institucionalização refere-se a um processo adaptativo pelo qual as expectativas sociais da forma mais apropriada de se organizar e de se comportar levam em conta determinadas regras vigentes.

A abordagem da teoria institucional tem sido aplicada em diversas pesquisas no campo da contabilidade gerencial. Covaleski e Dirsmith (1988a, 1988b) adotaram a perspectiva institucional para examinar a maneira pela qual expectativas sociais de práticas orçamentárias aceitáveis são articuladas, instituídas e modificadas durante um período de declínio na organização universitária. Esses autores descrevem o processo de como a universidade estudada desafiou e rejeitou o modelo tradicional de alocação de verbas orçamentárias quando o modelo tornou-se inconsistente com os interesses e objetivos da universidade, concluindo que o processo orçamentário é uma forma importante pela qual expectativas sociais são reproduzidas.

Ansari e Euske (1987) também utilizaram a perspectiva institucional para examinar o papel da informação contábil no setor público, identificando esse papel em termos de documentação da compliance organizacional, buscando a legitimação externa e a adaptação à realidade sociopolítica estabelecida. O estudo de como as informações de custos eram utilizadas no Departamento de Defesa americano identificou disparidades entre o objetivo formalmente definido do sistema de meIhorar a eficiência organizacional e a ausência de sistemas contábeis utilizados para essa finalidade.

No estudo de Mezias (1990) sobre as práticas de relatórios financeiros de empresas sem finalidades lucrativas, foi demonstrado o relacionamento entre determinadas variáveis institucionais e as práticas de relatórios financeiros, concluindose que o modelo institucional adiciona poder explicativo significativo no entendimento de modelos que dominam a literatura de economia aplicada.

Carruther (apud Covaleski et al., 1996) menciona que, de acordo com a teoria institucional, as práticas contábeis podem ser vistas como um grande conjunto de características que podem legitimar organizações por meio da construção de uma aparente racionalidade e eficiência. 
O trabalho de Granlund e Lukka (1998) objetiva identificar e analisar as forças que parecem causar convergência (em nível macro) nas práticas contábeis gerenciais nas empresas ao redor do mundo. Nesse trabalho é utilizada a abordagem NIS como meio básico para estruturar as análises institucionais.

NOVA ECONOMIA INSTITUCIONAL (NIE NEW IINSTITUTIONAI ECONOMICS)

Coase (1937), North (1992) e Williamson (1992) são os principais teóricos no âmbito da NIE. Roberts e Greenwood (1997) observam que a teoria dos custos de transação nasceu da questão original proposta por Coase (1937) - por que as organizações existem? - e citam uma outra questão proposta por Williamson (1992) - de forma particular, quais desenhos as organizações irão adotar sob várias circunstâncias? Ramstad (1996) observa que um importante elemento da teoria de Williamson é a mudança do foco da firma como uma função de produção, para a firma como uma estrutura de governança. Outro aspecto importante presente na visão de Williamson sobre a teoria de custos de transação é o conceito de racionalidade limitada dos agentes envolvidos.

A NIE abandona o pressuposto neoclássico da maximização da utilidade pelos indivíduos (Groenewegen, 2004), porém não rompe completamente com a teoria econômica neoclássica. Nesse sentido, Ankarloo e Palermo (2004, p. 413) observam que "[...] a nova economia institucional explica instituições capitalistas utilizando o ferramental neoclássico. Esse método consiste em introduzir instituições de fora do mercado como solução para as falhas de mercado". Os instrumentos dessa abordagem teórica são os arranjos institucionais de contratos e organizações em ambiente competitivo, cuja administração de firmas é disciplinada pela pressão competitiva dos mercados (de bens, de mão-de-obra etc.).

As instituições são vistas como as regras do jogo de uma sociedade, formadas por regras formais (leis e regras sociais) e por restrições informais (convenções e normas de comportamento) (NORTH, 1992). O governo é tido como o responsável pelas instituições formais de direito e pelo ambiente de regras formais. Assim, a NIE foca o ambiente institucional como um conjunto de regras sociais, legais e políticas que estabelecem as bases para a produção, a troca e a distribuição. O ambiente institucional é caracterizado como um elemento central para o entendimento da evolução de uma indústria e da estratégia das empresas nele inseridas. O ambiente institucional exerce uma grande influência no comportamento das organizações econômicas. Essas podem ser consideradas como grupos de indivíduos envolvidos por um propósito comum de alcançar seus objetivos por meio das transações com o mercado.

North (1992) observa que instituições são formadas para reduzir a incerteza nas trocas humanas e que, junto com a tecnologia, elas determinam os custos das transações. Esse autor (1992) enfatiza que foi Coase (1937) quem fez a conexão crucial entre instituições, custos de transação e teoria neoclássica. Os custos de transação surgem porque a informação possui um custo para ser gerada, sendo assimetricamente mantida pelos agentes nos seus relacionamentos. Os custos de mensurar as múltiplas dimensões de produtos e serviços trocados ou de mensurar os desempenhos dos agentes e, também, os custos de promover acordos caracterizam os custos de transação.

\section{VELIIA ECONOMIA INSTITUCIONAL (OIIE -} OID INSTITUTIONAL ECONOMICS)

A denominada velha economia institucional, pode-se dizer, forma um corpo teórico muito heterogêneo, pois são considerados, fazendo parte dessa corrente, autores como Karl Marx, Vilfredo Pareto, além daqueles considerados empiricistas, 
nacionalistas, influenciados pela biologia darwinista e vinculados à escola histórica alemã do último quartel do século XIX, como Gustav Schmoller, Adolph Wagner e Wilhem Roscher (SANTOS, 2003).

Considerando a teoria institucional segundo a ótica OIE, a instituição é o principal objeto de análise e não mais o comportamento racional e maximizador dos indivíduos tomadores de decisões. Assim, a conceituação de instituição é relevante, embora não exista uma definição simples e amplamente aceita de instituição. Scapens (1994) menciona que, no âmbito da OIE, a primeira definição de instituição foi dada por Veblen em 1919: "um determinado modo de pensar comum para um conjunto de pessoas". Santos (2003) enfatiza esse fato mencionando que talvez o personagem mais forte e influente da chamada Escola Institucionalista seja o economista e sociólogo norte-americano, de origem irlandesa, Thorstein Bunde Veblen (1857 - 1929), até porque é considerado o seu fundador. Já para Burns (2000), a idéia de instituição mais aplicada na OIE foi dada por Walton Hamilton em 1932, a qual considera instituição como uma forma de pensar ou agir de algo que prevalece, permanece e que está inserido nos hábitos de um grupo ou nos costumes de um povo. Essa definição traz à tona o caráter social e cultural, e enfatiza a importância do comportamento habitual.

A instituição diz respeito a uma forma e coerência social impostas sobre uma atividade humana, por meio da produção e reprodução de "hábitos estabelecidos de pensamento e ação" (Burns; Scapens, 2000, p. 6). As instituições desenvolvem-se pelo processo de rotinização da atividade humana. Dessa forma, as idéias de hábitos e instituições estão conectadas com o conceito de rotina. A caracterização de hábitos envolve uma pré-disposição ou tendência para se engajar em formas de ação anteriormente adotadas ou adquiridas. É importante observar que a existência de hábitos não exclui a idéia da intencionalidade do comportamento individual, e não significa que hábitos não possam ser modificados. Embora hábitos estejam na esfera pessoal, as rotinas podem envolver um grupo de pessoas, e assim as rotinas se tornam os principais componentes das instituições. Em outras palavras, as rotinas são hábitos formalizados e institucionalizados que incorporam comportamentos baseados em regras. Segundo Burns e Scapens (2000, p. 6), as regras podem ser definidas como "os meios formais reconhecidos pelos quais as coisas deveriam ser feitas". Scapens (1994) observa que as regras são necessárias para coordenar e dar coerência às ações de um grupo de pessoas, pois por meio da repetição do processo de atendimento às regras, o comportamento se torna programático. As rotinas representam formas de pensar e de agir que são habitualmente adotadas por um grupo de indivíduos de forma inquestionável; são os componentes das instituições. Num mundo complexo e de incertezas, hábitos e rotinas são úteis, já que é praticamente impossível para um indivíduo efetuar escolhas de alternativas na forma proposta pelo modelo econômico racional. Muito embora as empresas tenham o objetivo de lucro e os gestores tenham consciência e responsabilidade por buscar os melhores resultados para desempenhar o seu papel no dia-a-dia, os gestores precisam conhecer quais rotinas executar e quando. Essas dão coesão ao sistema empresa. Em síntese, as principais características de uma instituição são:

- Caráter coletivo: as instituições são estruturadas por meio de rotinas definidas por pensamentos e hábitos formalizados e aceitos por pessoas de um determinado grupo social.

- Caráter de dar significado ao comportamento organizacional: as instituições permitem aos indivíduos e grupos dentro da organização dar significado às suas atividades do dia-a-dia.

- Caráter objetivo: as instituições definem padrões de comportamento que são esperados de um determinado grupo social.

- Caráter normativo: as instituições geralmente espelham regras estabelecidas para a organização, porém isso nem sempre ocorre. Existem regras que não são aceitas pelo grupo social. 
- $\quad$ Caráter de não questionamento: os membros do grupo aceitam a instituição de forma inquestionável.

- Caráter repetitivo: a instituição implica em hábito, rotina e, portanto, em repetição de ações.

- Caráter de estabilidade: o período de tempo em que perduram as instituições é bastante variável. Existem instituições que possuem uma vida curta e outras, uma vida mais longa. Porém todas têm um certo período de tempo em que são prevalecentes e, durante esse período de tempo, existe estabilidade.

- Caráter de orientar ações: quanto mais ampla e profundamente uma instituição é aceita, mais provável é sua influência no sentido de direcionar ações e resistir a mudanças.

\section{A CONTABILIDADE GERENGIAL COMIO UNMA INSTITUIÇ $\widetilde{A} O$}

Scapens (1994) afirma que o conjunto de idéias contidas na teoria institucional - OIE estrutura um arcabouço intelectual mais adequado para o entendimento dos sistemas de contabilidade gerencial do que a estrutura conceitual do modelo neoclássico. Segundo esse autor, a abordagem das instituições não deve ser considerada nem a única nem o melhor approach, porém se apresenta como uma estrutura válida para o entendimento das práticas contábeis gerenciais como rotinas institucionalizadas e para explorar a interação entre a contabilidade gerencial e outras instituições sociais.

Burns e Scapens (2000) utilizam os conceitos de hábitos, regras, rotinas e instituições para sugerir como as práticas contábeis podem tornar-se rotinizadas e, através do tempo, começar a fazer parte do conjunto das pressuposições e crenças inquestionáveis da organização (taken for granted). A contabilidade gerencial, sob a ótica da regra, corresponde a um conjunto de técnicas e procedimentos definidos formalmente e registrados nos manuais de procedimentos. A contabilidade gerencial sob a ótica de rotina diz respeito ao conjunto de técnicas e procedimentos efetivamente utilizado. Práticas contábeis e rotinas emergentes podem ser caracterizadas como institucionalizadas quando elas se tornam amplamente aceitas na organização e quando elas se tornam formas de controle gerencial inquestionáveis. Não se pode afirmar que toda a contabilidade torna-se rotinizada e institucionalizada, porém existe um forte potencial para que isso ocorra. Assim, a contabilidade gerencial como uma instituição corresponde a um conjunto de rotinas institucionalizadas e aceitas na organização, devendo-se observar que a contabilidade gerencial tanto é moldada quanto impacta outras instituições no âmbito da organização.

De forma geral, o sistema de contabilidade gerencial pode ser visto como uma importante rotina no âmbito das organizações, ou ainda, a contabilidade gerencial pode ser enfocada como um conjunto fortemente estruturado de rotinas. Os orçamentos são elaborados, a performance monitorada e relatórios produzidos de um modo regular e rotineiro por meio de regras e procedimentos claramente especificados. A contabilidade gerencial estabelece uma estrutura fundamental para que os eventos econômicos sejam apresentados e representados para os membros da organização. A performance organizacional é reportada tanto interna como externamente de acordo com regras e convenções. Os eventos econômicos não falam por si mesmos; as atividades organizacionais são vistas pelas pessoas de acordo com a lógica da mensuração contábil.

Além de prover os meios para representar o desempenho, as regras e os procedimentos da contabilidade também definem os direitos dos grupos de indivíduos (donos, financiadores, gestores, trabalhadores etc.) e estabelecem as diretrizes para a implementação de ações (alocação de recursos, decisões operacionais, 
decisões de preços, etc.). Nesse contexto, mais do que adotar, na contabilidade gerencial, os preceitos da teoria convencional, ou seja, como geradora de informações para a tomada de decisões racionais para a maximização do lucro, deve ser explorada a extensão em que a contabilidade gerencial pode prover uma base institucional para a tomada de decisões e estruturar a formação de crenças e expectativas. A questão é o entendimento de como as práticas da contabilidade gerencial proporcionam coerência social, bem como significado ao comportamento organizacional, permitindo aos indivíduos e grupos dentro da organização dar significado às suas atividades do dia-a-dia. Quando as práticas contábeis tornam-se rotinas institucionalizadas, seus papéis no processo organizacional e na tomada de decisões são totalmente aceitos pelos membros da organização. A contabilidade, dessa forma, torna-se um mecanismo que dá sentido às atividades empresariais e que intervém como mediadora de potenciais conflitos dentro da organização. Por outro lado, a referida institucionalização pode não ser sempre prontamente alcançada. Podem existir conflitos e resistência sobre novos sistemas contábeis e, ainda, a contabilidade pode não ser a forma dominante de controle organizacional. Deve prevalecer uma orientação holística da teoria institucional no estudo das contribuições da contabilidade gerencial para o processo institucionalizado de tomada de decisões. Assim, é importante estudar o relacionamento entre as práticas da contabilidade gerencial com outras rotinas da organização, bem como considerar os diferentes aspectos da teoria institucional como, por exemplo, o papel das instituições e rotinas no processo de prover legitimidade às atividades organizacionais ou o papel de mediadora de potenciais conflitos internos.

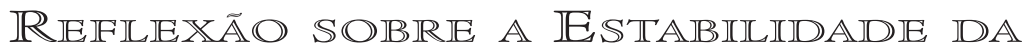 CONTABILIDADE GERENCIAL}

O enfoque institucional fornece uma perspectiva alternativa para o estudo das práticas da contabilidade gerencial. Essa perspectiva induz o pesquisador a uma análise detida da natureza das práticas vigentes na empresa. Muito mais do que desqualificar determinadas práticas da contabilidade gerencial que não se conformam com as diretrizes das modernas teorias apresentadas nos livros-texto, a contabilidade gerencial deve ser estudada como um produto de processos institucionais nos quais hábitos e rotinas são desenvolvidos para dar coerência e significado para o comportamento da organização. Novas técnicas e procedimentos de contabilidade gerencial são introduzidos na organização ao longo do tempo por meio da ação dos contadores e gestores, bem como pelo processo de institucionalização (formação de hábitos e rotinas). Essas novas técnicas e rotinas desenvolvem-se e adaptam-se às condições ambientais e, dessa forma, tornamse instituições amplamente aceitas no âmbito das organizações. Por outro lado, o monitoramento reflexivo sobre essas práticas também pode encorajar adaptações, modificações e até mesmo a exclusão de tais rotinas. A implementação gradativa de novas técnicas e procedimentos pode-se dar por um processo de acomodação com as demais rotinas da empresa, caracterizando uma mudança evolucionária. Por outro lado, técnicas e procedimentos completamente diferentes e alternativos aos usualmente empregados na empresa podem ser criados e implementados, caracterizando uma mudança revolucionária.

As pesquisas empíricas demonstram que os novos modelos de contabilidade gerencial têm tido baixo grau de implementação prática. À luz da abordagem da nova sociologia institucional (NIS - new institutional sociology), isso explica-se na medida em que novos conceitos propostos não estão em linha com as expectativas dos indivíduos da organização, ou não estão em conformidade com as normas sociais de comportamento aceitável na empresa. O comportamento dos gestores empresariais não é orientado somente pela racionalidade econômica conforme pressupostos da teoria neoclássica da firma. Existem ou- 
tras variáveis que orientam o comportamento dos indivíduos e explicam porque modernos sistemas de contabilidade gerencial têm pouca implementação prática nas empresas.

Considerando a teoria institucional segundo a ótica OIE (old institutional economics), a contabilidade gerencial pode ser vista como uma instituição, ou seja, um conjunto de rotinas que representam os hábitos de um conjunto de indivíduos e fazem parte do conjunto das pressuposições e crenças inquestionáveis da organização (taken for granted). Como já mencionado, as práticas da contabilidade gerencial proporcionam coerência social, bem como significado ao comportamento organizacional, permitindo aos indivíduos e grupos dentro da organização dar significado às suas atividades do dia-a-dia. A introdução de um novo modelo traz insegurança, riscos, questionamento da competência dos indivíduos de lidar com novas variáveis, deslocamento do eixo do poder. Neste contexto, as questões que podem ser efetuadas pelos gestores são: Por que (eu) irei apoiar essa aventura? O que (nós) ganharemos com isso?

A estabilidade confere segurança aos indivíduos, saber como será o amanhã é psicologicamente mais confortável do que enfrentar os riscos de uma expectativa incerta. Os indivíduos na organização tomam decisões sobre eventos econômicos em grande parte repetitivos. Assim, o processo de tomada de decisões, de acordo com certas regras e padrões previamente estabelecidos na organização, propicia uma certa estabilidade e tranqüilidade porque seus resultados podem ser antecipados, bem como podem ser antecipadas as possíveis avaliações sobre tais resultados.

O processo de institucionalização de um novo sistema de contabilidade gerencial não é trivial e não pode ser enfocado apenas na dimensão técnica. À luz das considerações efetuadas, para que os indivíduos passem a aceitar um novo modelo de contabilidade gerencial e se comprometam firmemente com a sua implementação e utilização, é necessária a integração de diversos fatores:

- Que exista uma orientação normativa no sentido da implementação do novo modelo;

- Que o novo modelo seja efetivamente compreendido pelas pessoas;

- Que existam elementos facilitadores para o processo de repetição do modelo proporcionando certa estabilidade e gerando hábitos;

- Que as pessoas percebam claramente as conseqüências da implantação do modelo, no plano pessoal;

- Que as pessoas percebam claramente as conseqüências da implantação do modelo, no âmbito do grupo;

- Que a implementação do novo modelo confira legitimidade para as pessoas, tanto no âmbito interno quanto externo;

- Que o novo modelo esteja sintonizado com as crenças e valores aceitos e compartilhados pelos membros da organização; e

- Que o novo modelo represente efetivamente como os indivíduos serão avaliados não só institucionalmente, mas também subjetivamente pelos seus pares.

Para que um novo modelo de contabilidade gerencial se torne uma efetiva instituição da organização é preciso o atendimento de vários quesitos conforme acima descrito. Evidentemente não podem ser desconsideradas outras variáveis importantes na implementação do novo modelo como tecnologia de informação, recursos, competência técnica, liderança no projeto, apoio da alta administração, entre outras. A dimensão técnica, no entanto, fica em segundo plano. Na prática, a discussão, por exemplo, sobre a adoção do método de custeio variável ou método de custeio por absorção não é tão relevante (essa discussão só é relevante no meio acadêmico). A teoria corrente propõe que, para análise de rentabilidade, deva ser utilizado o método de custeio variável, por outro lado, pesquisas indicam que a maior parte das empresas no mundo todo utiliza o método de custeio por absorção. Na prática, os sistemas de contabilidade gerencial não incorporam necessariamente os melhores conceitos técnicos ditados pela teoria convencional, 
mas sim os conceitos que estejam em linha com as expectativas dos indivíduos e em conformidade com as normas sociais de comportamento aceitável na empresa e que se convertam em hábitos e rotinas amplamente aceitos pelos indivíduos da organização.

\section{CONSIDERAÇÕES IFINAIS}

A questão de reflexão colocada no âmbito deste trabalho é: por que as empresas têm apresentado baixo grau de implementação de novos conceitos de contabilidade gerencial? Uma análise detida das características do ambiente social e empresarial moderno demonstra que as empresas estão trabalhando em ambiente mais competitivo e desafiador do que há vinte ou trinta anos, demandando, a princípio, a implementação de novas abordagens conceituais de contabilidade gerencial. O que observa-se, porém, é que a contabilidade gerencial das empresas não tem se alterado significativamente. É possível constatar o gap existente entre a teoria convencional e a prática empresarial.

Ao longo do trabalho foi argumentado que a teoria convencional de contabilidade gerencial inspira-se no modelo econômico neoclássico o qual envolve as idéias da racionalidade do tomador de decisões na busca pela maximização de resultados, da assimetria informacional, da ausência de custos de transação e da inexistência de conflitos de agência. Sob essa abordagem, a distância existente entre teoria e prática é um paradoxo, uma vez que os sistemas de contabilidade gerencial "otimizadores" de resultados deveriam ser amplamente utilizados, mas não o são. A questão das mudanças na contabilidade gerencial, neste trabalho, foi enfocada de acordo com a teoria institucional, especificamente sob o enfoque da OIE - old institutional economics. Essa abordagem ajuda os gestores a entenderem o paradoxo entre o que diz a teoria e o que as empresas fazem na prática em termos de contabilidade gerencial.

As reflexões efetuadas sobre a contabilidade gerencial à luz da OIE oferecem uma possível resposta à questão de pesquisa levantada, qual seja: as empresas não utilizam em larga escala novas abordagens de contabilidade gerencial porque os processos de institucionalização dos novos conceitos efetivamente não ocorreram. Os novos conceitos não se converteram em hábitos de grupos dentro da organização que são a base das rotinas e das instituições. Diversos fatores explicam essa não institucionalização de novos conceitos, sendo que, no âmbito deste trabalho, destacam-se: (i) fraca orientação normativa no sentido da implementação dos novos modelos; (ii) ausência de elementos facilitadores para o processo de repetição dos modelos, proporcionando certa estabilidade e gerando hábitos; (iii) baixo grau de compreensão dos sistemas pelas pessoas; (iv) baixo grau de percepção pelas pessoas das conseqüências da implantação dos modelos, no plano pessoal; ( $v$ ) baixo grau de percepção pelas pessoas das conseqüências da implantação dos modelos, no âmbito do grupo; (vi) a não percepção pelas pessoas de que os novos modelos lhes conferem legitimidade, tanto no âmbito interno quanto externo; (vii) falta de sintonia dos sistemas com as crenças e valores aceitos e compartilhados pelos membros da organização; e (viii) os novos modelos não representam, efetivamente, como os indivíduos serão avaliados, não só institucionalmente, mas, também, subjetivamente pelos seus pares.

De forma geral, as novas abordagens de contabilidade gerencial continuam a seguir prioritariamente as antigas premissas do modelo econômico neoclássico. Embora não se possa desconsiderar que os gestores tenham a preocupação com a maximização dos resultados de suas decisões, é pouco provável que eles tenham uma postura orientada somente pela dimensão racional do ser humano. A contabilidade gerencial orientada pela postura racional não propicia todas as respostas que as pessoas esperam, ou seja, a prática da contabilidade gerencial é influenciada por outras variáveis de caráter social no ambiente da organização. A teoria institucional, nesse contexto, apresenta-se como uma forma alternativa 
válida de analisar e explicar a prática da contabilidade gerencial. Dessa forma, a contabilidade gerencial é vista como uma instituição orientada, principalmente, para dar respostas, prioritariamente, às questões sociais dos grupos da organização e não, necessariamente, às questões racionais.

Finalmente, deve ser considerado que este trabalho de caráter eminentemente teórico apresenta um enfoque alternativo para subsidiar estudos de implementação prática da contabilidade gerencial, bem como serve para embasar estudos empíricos na forma de estudos de casos para o entendimento das causas da não institucionalização dos novos enfoques da contabilidade gerencial. Do ponto de vista de futuras pesquisas, é importante ressaltar a relevância de trabalhos que investiguem as relações entre as instituições e as práticas gerenciais como elas efetivamente ocorrem e não apenas como elas deveriam ser (abordagem normativa). Diversos estudos podem ser conduzidos no sentido de ampliar o entendimento da contabilidade gerencial e de como ela é operacionalizada nas organizações. Como exemplo ilustrativo, pode-se citar o problema da definição do método de custeio. É possível observar que existem diversos trabalhos que discutem os vários métodos de custeio, no entanto parece não haver interesse dos pesquisadores em entender como os métodos de custeio interagem, por exemplo, com as diversas formas de estruturas organizacionais. Será que determinado método pode ser mais facilmente institucionalizado em organizações com determinadas características pré-definidas? A pesquisa em contabilidade gerencial tem um enorme potencial de crescimento, tendo como base o entendimento de como as práticas gerenciais realmente ocorrem e de como elas se relacionam com a estrutura da firma. Essa abordagem parece ser mais rica em possibilidades do que a pura normatização de práticas e procedimentos.

$\mathbb{R} \mathbb{E} \mathbb{E} \mathbb{R} \hat{\mathbb{E}} \mathbb{N} \mathbb{C} \mathbb{S}$

ANKARLOO, D.; PALERMO, G. Anti-Williamson: a Marxian critique of new

institutional economics. Cambridge Journal of Economics, v. 28, n.3, p. 313-429, 2004.

ANSARI, S.L.; EUSKE K.J. Rational, rationalizing and reifying uses of accounting data in organizations. Accounting, Organizations and Society, n. 12, p. 549-570, 1987.

ASK, U.; AX, C. Trends in the development of product costing practices and techniques - a survey of Swedish manufacturing industry. In: $15^{\text {th }}$ ANNUAL CONGRESS OF THE EUROPEAN ACCOUNTING ASSOCIATION, 1992, Madri. Anais... Madri, 1992.

BAINES, A.; LANGFIELD-SMITH, K. Antecedents to management accounting change: a structural equation approach. Accounting, Organizations and Society, $\mathrm{n}$. 28, p. 675-698, 2003.

BRIGTH, J.; DAVIES, R. E.; DOWNES, C.A.; SWEETING, R.C. The deployment of costing techniques and practices: a UK study. Management Accounting, n. 3, p. 201-212, 1992.

BURNS, J. The dynamics of accounting change: inter-play between new practices, routines, institutions, power and politics. Accounting, Auditing \& Accountability Journal, n. 13, p. 566-596, 2000.

BURNS, J.; SCAPENS, R. W. Conceptualizing management accounting change: an institutional framework. Management Accounting Research, n. 11, p. 3-25, 2000.

CHOUDHURY, N. In search of relevance in management accounting research. Accounting and Business Research, Winter, p. 21-26, 1986. 
COAD, A. F. Some survey evidence on the learning and performance orientations of management accountants. Management Accounting Research, n. 10, p. 109135, 1999.

COASE, R. H. The nature of the firm. Economica, n. 4, p. 386-405, nov. 1937.

COHEN, J. R.; PAQUETTE, L. Management accounting practices: perceptions of controllers. Journal of Cost Management for the Manufacturing Industry, p. 73-83, 1991.

COVALESKI, M. A.; DIRSMITH, M. W. The use of budgetary symbols in the political arena: an historically informed field study. Accounting, Organizations and Society, n. 13, p. 1-24, 1988(a).

COVALESKI, M. A.; DIRSMITH, M. W. An institutional perspective on the rise, social transformation, and fall of a university budget category. Administrative Science Quarterly, n. 33, p. 562-582, 1988(b).

COVALESKI, M. A.; DIRSMITH, M. W.; SAMUEL, S. Managerial accounting research: the contributions of organizational and sociological theories. Journal of Management Accounting Research, n. 8, p. 1-35, 1996.

DIMAGGIO, P. J.; POWELL, W.W. The iron cage revisited: institutional isomorphism and collective rationality in organizational fields. American Sociological Review, n. 48, p. 147-160, 1983.

DRURY, C.; BRAUND, S.; OSBORNE, P.; TAYLES, M. A survey of management accounting practices in UK manufacturing companies. Chartered Association of Certified Accountants, 1993.

EDWARDS, K. A.; EMMANUEL, C.R. Diverging views on the boundaries of management accounting. Management Accounting Research, n. 1, p. 551-563, 1990.

EMORE, J. R.; NESS, J.A. The slow pace of meaningful changes in cost systems. Journal of Cost Management for the Manufacturing Industry, Winter, p. 36-45, 1991.

EVANS, H.; ASHWORTH, G. Survey conclusion: make up to the competition. Management Accounting (UK), n. 74, p. 16-18, 1996.

FECHNER, H. E. O Custeio Baseado em Atividades pode ser melhorado pela análise $A B C$ ? Revista de Contabilidade do CRC-SP, p. 8-19, São Paulo, jun. 1999.

FONSECA, V.; MACHADO-DA-SILVA, C. L. Conversação entre abordagens da estratégia em organizações: escolha estratégica, cognição e instituição. Organizações e Sociedade, v. 9, n. 25, p. 93-109, 2002.

GRANLUND, M. Towards explaining stability in and around management accounting systems. Management Accounting Research, n. 12, p. 141-146, 2001.

GRANLUND, M.; LUKKA, K. It's a small world of management accounting practices. Journal of Management Accounting Research, n. 10, p. 153-179, 1998.

GREEN, F. B.; AMENKHIENAN, F. E. Accounting inovations: a cross sectional survey of manufacturing firms. Journal of Cost Management for the Manufacturing Industry, Spring, 1992.

GROENEWEGEN, J. Who should control de firm? Insights from new and original institutional economics. Journal of Economic Issues, n. 2, jun. 2004.

HOPWOOD, A. The archaeology of accounting systems. Accounting, Organizations and Society, n. 12, p. 207-234, 1987.

HORNGREN, C. T.; FOSTER, G.; DATAR, S. M. Contabilidade de custos. $9^{\text {a }}$ ed. Rio de Janeiro: LTC-Livros Técnicos e Científicos Editora S.A., 2000. 
JOHNSON, H. T.; KAPLAN, R. S. Relevance lost-the rise and fall of management accounting. Boston: Harvard Business School Press, 1987.

LIBBY, T.; WATERHOUSE, J. H. Predicting change in management accounting system. Journal of Management Accounting Research, n. 8, p. 137-150, 1996.

MEYER, J. W.; ROWAN, B. Institutionalized organizations: formal structures as myth and ceremony. American Journal of Sociology, n. 83, p. 340-363, 1977.

MEZIAS S. J. An institutional model of organizational practice: financial reporting at the Fortune 200. Administrative Science Quarterly, n. 35, p. 431-457, 1990.

NORTH, D. C. Institutions and economic theory. The American Economist, v. 36, n.1, 1992.

OTLEY, D. T. Developments in management accounting research. Management Accounting, p. 37-42, sep. 1985.

RAMSTAD, Y. Is a transaction a transaction? Journal of Economic Issue, n. 2, jun. 1996.

RICCIO, L. E.; SECURA, L. C.; SAKATA, M. C. G. Estudo das pesquisas sobre custos período de 1967 a 1999. Revista de Contabilidade do CRC-SP, p. 6-15, São Paulo, jun. 2000.

ROBERTS, P. W.; GREENWOOD, R. Integrating transaction cost and institutional theories: toward a constrained-efficiency framework for understanding organizational design adoption. The Academy of Management Review, v. 22, n. 2, p. 346, 1997.

RYAN, B.; SCAPENS, R. W. ; THEOBALD, M. Research method and methodology in finance and accounting. $2^{\text {nd }}$ ed., London: Thomson, 2002.

SANTOS, R. S. As contribuições dos economistas ao estudo da administração política: o institucionalismo, o gerencialismo e o regulacionismo. Organizações e Sociedade, v. 10, n. 28, p. 99-116, 2003.

SCAPENS, R. W. Never mind the gap: towards an institutional perspective on management accounting practice. Management Accounting Research, n. 5, p. 301321, 1994.

SCAPENS, R.W.; ROBERTS, J. Accounting and control: a case study of resistance to accounting change. Management Accounting Research n. 4, p. 1-32, mar. 1993. SCOTT, W. R. Institutions and organizations. Thousand Oaks, California: Sage, 1995.

WILLIAMSON, O. Markets, hierarchies, and the modern corporation: an unfolding perspective. Journal of Economic Behavior and Organization, n. 17, p. 335-352, 1992.

ZUCKER, L. G. Institutional theories of organizations. Annual Review of Sociology, n. 13, p. 443-464, 1987. 